\title{
Three hundred robotic-assisted mitral valve repairs: The Cedars-Sinai experience
}

\author{
Danny Ramzy, MD, PhD, Alfredo Trento, MD, Wen Cheng, MD, Michele A. De Robertis, RN, BS, \\ James Mirocha, MS, Andrea Ruzza, MD, PhD, and Robert M. Kass, MD
}

\begin{abstract}
Objective: The study objective was to review our first 300 consecutive robotic-assisted mitral repairs performed from June 2005 to October 2012 and to compare the surgical outcomes of our previously reported initial 120 cases with the subsequent 180 procedures.
\end{abstract}

\begin{abstract}
Methods: Our initial 120 robotic-assisted mitral repairs were previously reported, and we now compare our early experience with the recent 180 consecutive procedures for a total of 300 robotic-assisted mitral repairs. There was no patient selection. Every patient in need of isolated mitral valve repair underwent this procedure. All patients received an annuloplasty band and 1 or more of the following: leaflet resection, secondary chordal transposition, or polytetrafluoroethylene neochordal replacement and edge-to-edge repair.
\end{abstract}

Results: All 300 patients had preoperative echocardiographic findings of severe mitral regurgitation. There were no differences $(P=$ not significant) between the initial and the recent cohorts for preoperative characteristics, including age ( $58.4 \pm 10.5$ years vs 59.9 years), female gender $(35.8 \%$ vs $36.1 \%)$, ejection fraction $(61.9 \%$ vs $60.6 \%$ ), congestive heart failure ( $35.0 \%$ vs $36.7 \%$ ), creatinine $(0.94 \mathrm{mg} / \mathrm{dL}$ vs $0.98 \mathrm{mg} / \mathrm{dL}$ ), and New York Heart Association class. The incidence of anterior and posterior leaflet prolapse was similar in both groups, whereas Barlow syndrome was higher in group $2(5.8 \%$ vs $27.8 \%)$. There was $1(0.33 \%)$ hospital mortality and no deaths in the last 180 cases. Overall, 8 patients $(2.7 \%)$ required subsequent mitral valve replacement via a median sternotomy, $6(5.0 \%)$ in the first group and $2(1.1 \%)$ in the second group $(P=.06)$. One patient in each group had mitral valve re-repair through a right mini-thoracotomy, and 1 patient in the first group required a mitral valve replacement via a mini-thoracotomy during the original procedure. Two of the 180 patients had documented cerebrovascular accident, but both fully recovered clinically. There was no cerebrovascular accident in the last 120 patients. Crossclamp times decreased from 116 minutes to 91 minutes in the second group despite starting a training program with a junior associate performing part of the procedure at the console in the last 100 cases. Post-pump echocardiograms showed no/trace mitral regurgitation in $86.1 \%$ of the last 180 patients and mild mitral regurgitation in $11.1 \%$. Follow-up echocardiography for the last 180 patients from 1 month to more than 1 year showed no/trace mitral regurgitation in $64.6 \%$ of patients and mild mitral regurgitation in $23.1 \%$ of patients. Seven patients $(10.8 \%)$ had moderate mitral regurgitation, and 1 patient $(1.5 \%)$ had severe mitral regurgitation.

Conclusions: The majority of complications and reoperations occurred early in our experience, especially using the first-generation da Vinci robot (Intuitive Surgical Inc, Sunnyvale, Calif). The newer da Vinci Si HD system with the addition of an adjustable left atrial roof retractor together with increased experience has made roboticassisted mitral repair of all types of degenerative mitral valve pathology reproducible. The training of young surgeons in a stepwise fashion in high-volume centers will help to avoid the complications encountered during the introduction of this technology. (J Thorac Cardiovasc Surg 2014;147:228-35)

The gold standard for the treatment of degenerative mitral valve (MV) disease remains surgical repair. The classic repair

\footnotetext{
From the Division of Cardiothoracic Surgery, Cedars-Sinai Medical Center, Los Angeles, Calif.

Disclosures: Alfredo Trento reports lecture fees from Abbott Cardiovascular. The other authors have nothing to disclose with regard to commercial support.

Presented at The American Association for Thoracic Surgery Mitral Conclave, New York, New York, May 2-3, 2013

Received for publication April 27, 2013; revisions received Aug 28, 2013; accepted for publication Sept 17, 2013; available ahead of print Nov 6, 2013.

Address for reprints: Danny Ramzy, MD, PhD, Division of Cardiothoracic Surgery, Cedars-Sinai Medical Center, 8700 Beverly Blvd, SCCT 2S03, Los Angeles, CA 90048 (E-mail: dannyramzy@yahoo.ca).

$0022-5223 / \$ 36.00$

Copyright (c) 2014 by The American Association for Thoracic Surgery

http://dx.doi.org/10.1016/j.jtcvs.2013.09.035
}

described by Carpentier ${ }^{1}$ with leaflet resection and annuloplasty remains the primary technique for mitral repair. Other techniques, such as the "American correction" chordae, have been introduced with similar success rates. Innovations in surgical approach over the past 20 years have led to the development of minimally invasive access to the MV. Right mini-thoracotomy with endoscopy enhancements has been used by several groups with outcomes comparable to those for the traditional sternotomy approach. ${ }^{3-6}$ Ten years ago, Felger and colleagues ${ }^{7,8}$ pioneered the use of the da Vinci Robotic Surgical System (Intuitive Surgical, Inc, Sunnyvale, Calif) for MV repair. Their excellent outcomes and those of others led to an increased use of the robotic approach to the MV. ${ }^{9-14}$ In 2005, our group developed a 

Abbreviations and Acronyms
$\mathrm{MR}=$ mitral regurgitation
$\mathrm{MV}=$ mitral valve
$\mathrm{TEE}=$ transesophageal echocardiography

robotic-assisted MV surgery program. This review describes our first 300 consecutive robotic-assisted mitral repairs performed from June 2005 to October 2012, and we compare the surgical outcomes of our previously reported initial 120 cases $^{9}$ with the subsequent 180 procedures.

\section{MATERIALS AND METHODS}

From June 2005 to October 2012, 300 patients underwent intent-to-treat robotic-assisted MV repair. Our selection criteria for robotic-assisted mitral repair were as follows: (1) inclusion criteria were all patients with mitral regurgitation (MR), and (2) exclusion criteria were patients requiring concomitant coronary artery bypass or aortic valve repair/replacement, or those with fused right pleura. In the last 100 patients, a computed tomography scan of the aorta was performed to assess for aortoiliac and ascending aortic disease. There was 1 intraoperative conversion to a right minithoracotomy before completion of the mitral repair. This was due to external instrument conflicts of the robotic arms that could not be resolved because of space limitations of working in a small right hemithorax. Otherwise, 299 patients achieved successful completion of the robotic MV repair. The data presented in this retrospective review were obtained from an institutionally supported Cardiothoracic Surgery Quality Assurance Database. This data review was approved by the Cedars-Sinai Institutional Review Board.

\section{Operative Technique}

Our current standard practice has been described. ${ }^{9}$ The first 74 cases were performed with the original model of the da Vinci Robotic Surgical System. For these cases, the handle of the atrial septal roof retractor (Cardiovations, Irvine, Calif) was inserted just lateral to the right intrathoracic artery. The last 226 cases were performed with the second-generation da Vinci Si HD, with a fourth articulating arm as a movable left atrial roof retractor.

After the patient is positioned supine with the right side of the chest elevated, the right lung is deflated, and a 3 to $4-\mathrm{cm}$ right infrathoracic incision through the fourth or fifth intercostal space is made as the working port. Trocars for the robotic instrument arms, 14-gauge angiocatheters for traction sutures, and a 20F DLP (Medtronic, Inc, Minneapolis, Minn) intracardiac sump drain are inserted through a separate stab-wound incision.

The patient is heparinized, and the femoral vessels are cannulated for cardiopulmonary bypass. A 2-stage venous cannula is placed through the femoral vein under transesophageal echocardiography (TEE) guidance to ensure proper placement for venous drainage with vacuum assistance. The pericardium is incised ventral to the phrenic nerve. A transthoracic aortic clamp (Scanlan International, Minneapolis, Minn) is positioned through the third intercostal space in the midaxillary line. An ascending aortic root vent (DLP 14-gauge 7F; Medtronic, Inc) is placed under direct vision. The da Vinci robot is positioned to the patient's left side, and the instrument arms are placed endoscopically. Bypass is established, and the patient is cooled to $32^{\circ} \mathrm{C}$. Once cold, the crossclamp is positioned and clamped under endoscopic vision. An amount of $120 \mathrm{~mL}$ of cold blood cardioplegia (Kp, mannitol, $\mathrm{HCO} 3$ mixture) is infused directly through the aortic root. Then, 200-mL doses of cold antegrade crystalloid cardioplegia are administered by the anesthesiologist approximately every 20 minutes after crossclamping to supplement the initial dose of cold blood cardioplegia. Once asystole is achieved, a standard left interatrial incision is made with the robot, and the left atrial roof retractor is positioned for MV exposure.
All patients received an annuloplasty band and 1 or more of the following: leaflet resection, secondary chordal transfer or neochordal replacement, or edge-to-edge repair. The edge-to-edge repair served as a commissural closure or in the p1-a1 and p3-a3 location in cases with residual regurgitation after testing the valve. No edge-to-edge repair was used as a bailout approach.

\section{Follow-up}

All surviving patients $(n=299)$ were examined and clinically evaluated within 2 weeks after hospital discharge. Further clinical follow-up was obtained through annual questionnaire, direct patient contact, or routine communication with the referring physicians, including echocardiogram reports. Overall, 97\% of patients had at least 1 follow-up echocardiogram for this review.

\section{Statistical Methods}

Numeric variables were summarized as means \pm standard deviations or medians (ranges). Categoric variables were summarized as frequencies (percentages). Numeric variables were compared across groups by the $t$ test or Wilcoxon rank-sum test, as appropriate. Categoric variables were compared across groups by the Fisher exact test. SAS version 9.2 (SAS Institute, Inc, Cary, NC) was used for all statistical calculations.

\section{RESULTS}

All 300 patients had preoperative echocardiographic findings of severe MR. All patients underwent functional valve assessment by intraoperative TEE, and the valve pathology was confirmed at operation.

There were no statistically significant differences between the first 120 patients and the second 180 patients for preoperative characteristics, including age $(58.4 \pm$ 10.5 years vs $59.9 \pm 11.4$ years $)$, female gender $(35.8 \%$ vs $36.1 \%$ ), ejection fraction $(61.9 \%$ vs $60.6 \%)$, congestive heart failure ( $35.0 \%$ vs $36.7 \%)$, creatinine $(0.94 \mathrm{mg} / \mathrm{dL}$ vs $0.98 \mathrm{mg} / \mathrm{dL}$ ), and New York Heart Association class (Table 1). The prevalence of anterior leaflet prolapse was higher in the later cohort $(21.7 \%$ vs $32.8 \%, P=.038)$, as well as the prevalence of Barlow syndrome $(5.8 \%$ vs $27.8 \% P<.0001)$. In addition, the frequency of leaflet cleft was higher in the last 180 patients compared with the first 120 patients $(8.3 \%$ vs $0 \%, P<.0006)$.

The type of MV repair differed between groups. All patients received an annuloplasty band. There was a significantly greater use of triangular resection and cleft closures in the last 180 patients compared with the first cohort (Table 2). Mitral ring size was larger in the last 180 patients (average $33 \pm 3 \mathrm{~mm}$ vs $36 \pm 3 \mathrm{~mm}, P<.0001$; \#37 ATS band [ATS Medical Inc, Minneapolis, Minn] used in $9.2 \%$ vs $24.4 \%$ of repairs and \#39 ATS band used in 5.8\% vs $23.9 \%$ of repairs, $P<.0001)$. In the last 180 patients, 5 had a previous failed MitraClip (Abbott Laboratories, Abbott Park, Ill) procedure.

The concomitant left-sided CryoMaze procedure was similar, $24.2 \%$ versus $22.2 \%$. However, there was an increase in the rate of left atrial appendage exclusion with a running 4-0 polytetrafluoroethylene suture between the first group and second group $(12.5 \%$ vs $22.2 \%, P=.034)$.

Crossclamp times decreased from $116 \pm 30$ minutes in the first group to $91 \pm 22$ minutes in the second group 
TABLE 1. Background and preoperative characteristics

\begin{tabular}{|c|c|c|c|c|}
\hline Variable & All 300 cases & First 120 cases & Second 180 cases & $P$ value \\
\hline Age, $y$, mean $\pm S D$ & $57.3 \pm 11.0$ & $58.4 \pm 10.5$ & $59.9 \pm 11.4$ & .24 \\
\hline BMI, $\mathrm{kg} / \mathrm{m}^{2}$, mean $\pm \mathrm{SD}$ & $25.30 \pm 4.01$ & $25.44 \pm 3.96$ & $25.20 \pm 4.04$ & .62 \\
\hline Creatinine, $\mathrm{mg} / \mathrm{dL}$, mean $\pm \mathrm{SD}$ & $0.97 \pm 0.35$ & $0.94 \pm 0.21$ & $0.98 \pm 0.42$ & .30 \\
\hline $\mathrm{EF}$, mean $\pm \mathrm{SD}$ & $61.1 \% \pm 8.3 \%$ & $61.9 \% \pm 8.2 \%$ & $60.6 \% \pm 8.4 \%$ & .20 \\
\hline Female, n $(\%)$ & $108(36.0)$ & $43(35.8)$ & $65(36.1)$ & .96 \\
\hline NYHA, n (\%) & & & & .35 \\
\hline Class 1 & $51(17.0)$ & $26(21.7)$ & $25(13.9)$ & \\
\hline Class 2 & $119(31.7)$ & $43(35.8)$ & $76(42.2)$ & \\
\hline Class 3 & $114(38.0)$ & $45(37.5)$ & $69(38.3)$ & \\
\hline Class 4 & $16(5.3)$ & $6(5.0)$ & $10(5.6)$ & \\
\hline CHF, n $(\%)$ & $108(36.0)$ & $42(35.0)$ & $66(36.7)$ & .77 \\
\hline HTN, n (\%) & $129(43.0)$ & $47(39.2)$ & $82(45.6)$ & .27 \\
\hline Smoke, n (\%) & $72(24.0)$ & $30(25.0)$ & $42(23.3)$ & .74 \\
\hline $\mathrm{DM}, \mathrm{n}(\%)$ & $12(4.0)$ & $3(2.5)$ & $9(5.0)$ & .37 \\
\hline Pre-AF (replacement), n (\%) & $99(33.0)$ & $37(30.8)$ & $62(34.4)$ & .53 \\
\hline CVA, n $(\%)$ & $11(3.7)$ & $4(3.3)$ & $7(3.9)$ & $>.99$ \\
\hline $\mathrm{CA}, \mathrm{n}(\%)$ & $37(12.3)$ & $20(16.7)$ & $17(9.4)$ & .074 \\
\hline Prior surgery, n (\%) & $1(0.3)$ & $0(0)$ & $1(0.6)$ & $>.99$ \\
\hline Total diseased vessels, $\mathrm{n}(\%)$ & & & & .73 \\
\hline 0 & $291(97.0)$ & $117(97.5)$ & $174(96.7)$ & \\
\hline 1 & $7(2.3)$ & $3(2.5)$ & $4(2.2)$ & \\
\hline 2 & $2(0.7)$ & $0(0)$ & $2(1.1)$ & \\
\hline
\end{tabular}

Numeric variables: $t$ test. Categoric variables: chi-square or Fisher exact test. $A F$, Atrial fibrillation; $B M I$, body mass index; $C A$, cancer; $C H F$, congestive heart failure; $C V A$, cerebrovascular accident; $D M$, diabetes mellitus; $E F$, ejection fraction; $H T N$, hypertension; NYHA, New York Heart Association; $S D$, standard deviation.

$(P<.0001)$ despite increased repair complexity and starting a training program with a junior associate performing part of the procedure at the console in the last 100 cases. Our longest crossclamp time was in group 1, at 221 minutes. Longer crossclamp times were associated with more complex procedures. Likewise, more complex cases were associated with longer pump times. Pump times decreased from $156 \pm 43$ minutes to $136 \pm 30$ minutes $(P<.0001)$.

\section{Morbidity and Mortality}

No significant differences in major adverse cardiac events were noted between groups. There was 1 hospital mortality in group 1 and no deaths in the last 180 cases. Overall, 8 patients $(2.7 \%)$ required subsequent $\mathrm{MV}$ replacement via a median sternotomy, $6(5.0 \%)$ in the first group and $2(1.1 \%)$ in the second group $(P=.06)$ (Table 3$)$. There were 6 neurologic events in the overall experience, with $4(3.3 \%)$ in group 1 and $2(1.7 \%)$ in group 2 $(P=.22)$. Two of the 4 patients in group 1 had persistent deficits, and the 2 patients in group 2 recovered completely before hospital discharge. There were no neurologic events in the last 120 patients.

The use of homologous blood products, including red blood cells, platelets, and cryotherapy, was similar between the first and second groups $(27.5 \%$ vs $28.9 \%, P=.79)$ (Table 3). The incidence of renal failure (creatinine $>2.0$ ) was low in both the first and second groups $(2.5 \%$ vs $3.3 \%, P=.75$ ) (Table 3 ).

There were no femoral artery or vein complications and no lymphoceles requiring surgical intervention. Hospital

TABLE 2. Repair characteristics

\begin{tabular}{|c|c|c|c|c|}
\hline Variable & All 300 cases & First 120 cases & Second 180 cases & $P$ value \\
\hline Mitral prosthetic ring, $\mathrm{n}(\%)$ & $300(100)$ & $120(100)$ & $180(100)$ & N/A \\
\hline Mitral ring size, $\mathrm{mm}$, mean $\pm \mathrm{SD}$ & $34.7 \pm 3.0$ & $33.3 \pm 2.9$ & $35.9 \pm 2.8$ & $<.0001$ \\
\hline Quadrangular resection, n (\%) & $53(17.7)$ & $46(38.3)$ & $7(3.9)$ & $<.0001$ \\
\hline Triangular resection, $\mathrm{n}(\%)$ & $188(62.7)$ & $38(31.7)$ & $150(83.3)$ & $<.0001$ \\
\hline Chordal transposition, $\mathrm{n}(\%)$ & $50(16.7)$ & $15(12.5)$ & $35(19.4)$ & .114 \\
\hline Artificial chordae, n (\%) & $33(11.0)$ & $26(21.7)$ & $7(3.9)$ & $<.0001$ \\
\hline Edge-to-edge A1, P1, n (\%) & $23(7.7)$ & $8(6.7)$ & $15(8.3)$ & .66 \\
\hline Edge-to-edge A3, P3, n (\%) & $21(7.0)$ & $6(5.0)$ & $15(8.3)$ & .36 \\
\hline Cleft closure, n (\%) & $16(5.3)$ & $1(0.8)$ & $15(8.3)$ & .003 \\
\hline MitraClip (Abbott Laboratories, Abbott Park, Ill) removal, n (\%) & $5(1.7)$ & $0(0)$ & $5(2.8)$ & 16 \\
\hline
\end{tabular}

$N / A$, Not available; $S D$, standard deviation. 
TABLE 3. Postoperative outcomes and complications

\begin{tabular}{|c|c|c|c|c|}
\hline Outcome/complication & All 300 cases & First 120 cases & Second 180 cases & $P$ value \\
\hline 30-d mortality, n (\%) & $1(0.3)$ & $1(1.0)$ & $0(0)$ & .33 \\
\hline Late mortality, n (\%) & $2(0.7)$ & $2(1.7)$ & $0(0)$ & .16 \\
\hline MI, n (\%) & $1(0.3)$ & $1(0.8)$ & $0(0)$ & .40 \\
\hline Stroke (neurologic), n (\%) & $6(1.7)$ & $4(2.5)$ & $2(1.1)$ & .39 \\
\hline Reversible neurologic injury, $\mathrm{n}(\%)$ & $2(0.7)$ & $1(0.8)$ & $1(0.6)$ & $>.99$ \\
\hline Reoperation for bleed, n (\%) & $14(4.7)$ & $7(5.8)$ & $7(3.9)$ & .58 \\
\hline Reoperated valve, n (\%) & $13(4.3)$ & $10(8.3)$ & $3(1.7)$ & .008 \\
\hline Any blood product, $\mathrm{n}(\%)$ & $169(56.3)$ & $45(37.5)$ & $124(68.9)$ & $<.0001$ \\
\hline $\mathrm{pRBC}$ & $76(25.3)$ & $24(20.0)$ & $52(28.9)$ & .083 \\
\hline Platelets & $85(28.3)$ & $33(27.5)$ & $52(28.9)$ & .79 \\
\hline FFP & $155(51.7)$ & $36(30.0)$ & $119(66.1)$ & $<.0001$ \\
\hline Cryotherapy & $4(1.3)$ & $1(0.8)$ & $3(1.7)$ & .65 \\
\hline Infection, $\mathrm{n}(\%)$ & $1(0.3)$ & $0(0)$ & $1(0.6)$ & $>.99$ \\
\hline Creatinine $>2, \mathrm{n}(\%)$ & $9(3.0)$ & $3(2.5)$ & $6(3.3)$ & .75 \\
\hline AF/flutter (SVT), n (\%) & $61(20.3)$ & $18(15.0)$ & $43(23.9)$ & .061 \\
\hline New-onset AF/A flutter, $\mathrm{n}(\%)$ & $47(5.7)$ & $16(13.3)$ & $31(17.2)$ & .42 \\
\hline Pleural effusion, n (\%) & $7(2.3)$ & $2(1.7)$ & $5(2.8)$ & .71 \\
\hline Diaphragm paralysis, $\mathrm{n}(\%)$ & $1(0.3)$ & $1(0.8)$ & $0(0)$ & .40 \\
\hline Needle lost, $\mathrm{n}(\%)$ & $1(0.3)$ & $1(0.8)$ & $0(0)$ & .40 \\
\hline Hospital LOS, mean \pm SD & $6.0 \pm 2.9$ & $6.3 \pm 3.9$ & $5.8 \pm 2.0$ & .21 \\
\hline \multicolumn{5}{|l|}{ Repair failures and second operation } \\
\hline Mitral replacement, sternotomy & $8(2.7)$ & $6(5.0)$ & $2(1.1)$ & .063 \\
\hline Mitral replacement, minithoracotomy & $1(0.3)$ & $1(0.8)$ & $0(0)$ & .40 \\
\hline Mitral re-repair, sternotomy & $2(0.7)$ & $2(1.7)$ & $0(0)$ & .16 \\
\hline Mitral re-repair, minithoracotomy & $2(0.7)$ & $1(0.8)$ & $1(0.6)$ & $>.99$ \\
\hline
\end{tabular}

length of stay was similar between the first group $(6.3 \pm 3.9$ days, with only $1[0.8 \%]$ patient requiring readmission within 30 days) and the second group $(5.8 \pm 2.0$ days, with no readmission) (Table 3). Repair failures requiring a second operation were reduced from $8.3 \%$ in the first group to $1.7 \%$ in the second group $(P=.008)$.

Rare complications, such as diaphragm paralysis and lost needle, occurred only in the first 120 cases ( 1 each). Two patients were subsequently found to have occluded coronaries, 1 in each group. One patient required a stent for kinking of the proximal obtuse marginal, and 1 patient was not treated because it was a distal occlusion.

\section{Echocardiographic Studies and Patient Follow-up}

All 300 patients had severe MR as measured by preoperative transthoracic echocardiogram and confirmed with intraoperative TEE. There were 2 patients with post-pump TEE demonstrating moderately severe MR requiring valve replacement in group 1 compared with zero patients in group 2. Mean echocardiographic follow-up was $990 \pm$ 61 days for group 1 and $267 \pm 204$ days for group 2 .

Post-pump echocardiograms showed no significant differences in MR grade between groups $(P=.43)$ (Figure 1 and Table 4). No/trace MR was seen in $82.3 \%$ of patients in group 1 versus $86.1 \%$ of patients in group 2 .
Mild MR was seen in $16.8 \%$ of patients in group 1 versus $11.1 \%$ of patients in group 2 . Follow-up echocardiography from 1 month to 1 year showed no/trace MR in $64 \%$ of patients in group 1 versus $64.4 \%$ of patients in group 2 , and mild MR in $22.7 \%$ of patients in group 1 versus $21.7 \%$ of patients in group 2 (Table 4). More than 1-year followup in group 1 showed 7 patients $(7.4 \%)$ with moderate MR and 3 patients $(3.2 \%)$ with severe MR compared with 2 patients $(4.3 \%)$ with moderate MR and 2 patients $(4.3 \%)$ with severe MR in group 2 . Overall, the frequency of severe MR after 1 year was low at $3.5 \%$, with a rate of moderate MR of $6.3 \%$ (Table 4 ).

There was 1 death and 10 failed repairs, defined as symptomatic severe MR, in the first 120 patients, whereas there was no death and 3 failed repairs in the last 180 patients. In addition, we are following 4 patients experiencing no symptoms with severe MR in the first cohort and 1 patient in the later cohort.

\section{DISCUSSION}

Since October 2000, the use of robotic mitral repair has steadily grown. Our experience dates back to 2005. All patients with MR considered repairable were approached using the da Vinci system. With increasing experience and improved outcomes compared with the standard 

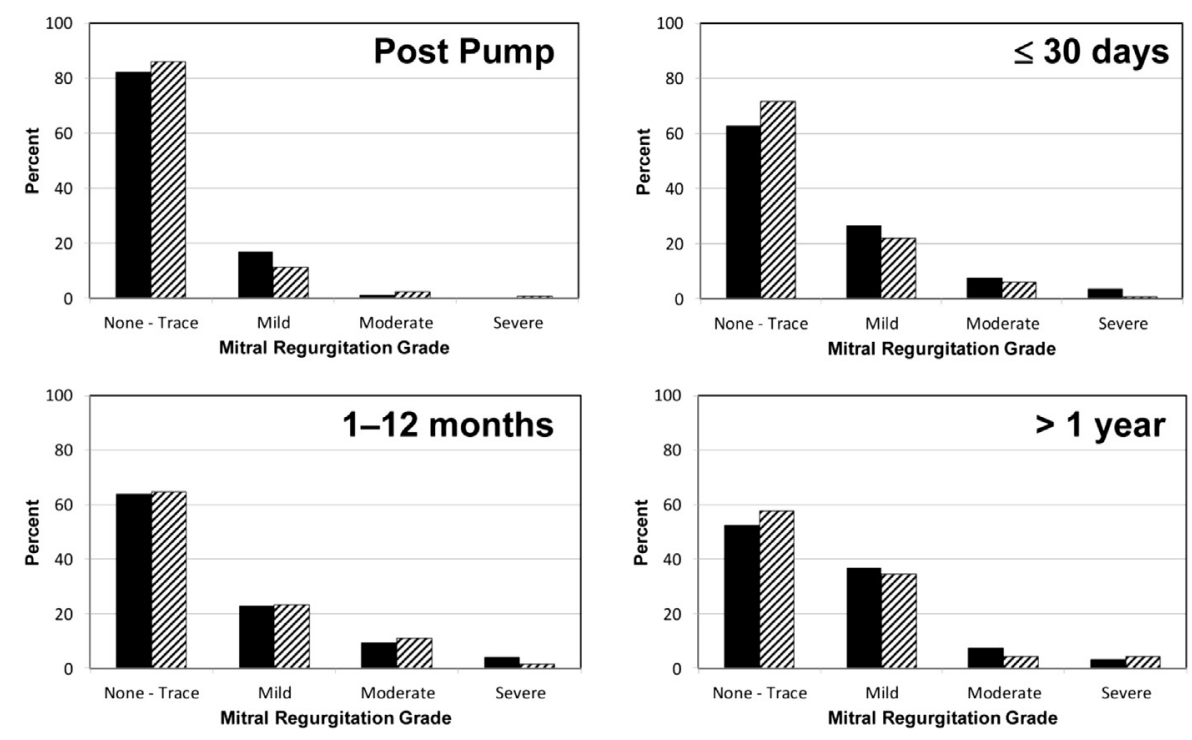

First $120 \square$ Second 180

FIGURE 1. Echocardiographic follow-up: Severity of mitral regurgitation.

sternotomy approach, we found an increase in referral of more complex mitral pathology leading to a greater proportion of patients with bileaflet pathology and Barlow's disease. The older da Vinci robotic system was used in the first 74 cases, which lacked the adjustable fourth arm. The next-generation system was used in the next 225 cases. All failed repairs requiring replacements were in patients performed with the first-generation robot. Using the newer generation da Vinci system greatly improved visualization and conduct of the operation. The adjustable fourth arm allowed for efficient manipulation of retraction to improve visualization for any given stitch. Furthermore, the ability to release retraction and test the valve also increased our success rate. There was 1 death and 10 failed repairs in the first 120 patients, whereas there was no death and 3 failed repairs in the last 180 patients. There are 4 patients

TABLE 4. Echocardiography follow-up: Mitral regurgitation grade

\begin{tabular}{|c|c|c|c|c|c|}
\hline & Preoperative & Post-pump & $\leq \mathbf{3 0}$ d & $1-12 \mathrm{mo}$ & $>1 \mathbf{y}$ \\
\hline Overall MR severity in 300 cases & $(\mathrm{n}=300)$ & $(\mathrm{n}=299)$ & $(\mathrm{n}=276)$ & $(\mathrm{n}=140)$ & $(\mathrm{n}=142)$ \\
\hline None & & $184(61.5)$ & $108(39.1)$ & $46(32.9)$ & $31(21.8)$ \\
\hline Trace & & $69(23.1)$ & $80(29.0)$ & $44(31.4)$ & $46(32.4)$ \\
\hline Mild & & $40(13.4)$ & $65(23.6)$ & $32(22.9)$ & $51(35.9)$ \\
\hline Moderate & & $5(1.7)$ & $18(6.5)$ & $14(10.0)$ & $9(6.3)$ \\
\hline Severe & $300(100)$ & $1(0.3)$ & $5(1.8)$ & $4(2.9)$ & $5(3.5)$ \\
\hline First 120 cases & $(\mathrm{n}=120)$ & $(\mathrm{n}=119)$ & $(\mathrm{n}=110)$ & $(\mathrm{n}=75)$ & $(\mathrm{n}=95)$ \\
\hline \multicolumn{6}{|l|}{ MR severity } \\
\hline None & & $65(54.6)$ & $37(33.6)$ & $23(30.7)$ & $21(22.1)$ \\
\hline Trace & & $33(27.7)$ & $32(29.1)$ & $25(33.3)$ & $29(30.5)$ \\
\hline Mild & & $20(16.8)$ & $29(26.4)$ & $17(22.7)$ & $35(36.8)$ \\
\hline Moderate & & $1(0.8)$ & $8(7.3)$ & $7(9.3)$ & $7(7.4)$ \\
\hline Severe & $120(100)$ & $0(0)$ & $4(3.6)$ & $3(4.0)$ & $3(3.2)$ \\
\hline Second 180 cases & $(\mathrm{n}=180)$ & $(\mathrm{n}=180)$ & $(n=166)$ & $(\mathrm{n}=65)$ & $(n=47)$ \\
\hline \multicolumn{6}{|l|}{ MR severity } \\
\hline None & & $119(66.1)$ & $71(42.8)$ & $23(35.4)$ & $10(21.3)$ \\
\hline Trace & & $36(20.0)$ & $48(28.9)$ & 19 (29.2) & $17(36.2)$ \\
\hline Mild & & $20(11.1)$ & $36(21.7)$ & $15(23.1)$ & $16(34.0)$ \\
\hline Moderate & & $4(2.2)$ & $10(6.0)$ & $7(10.8)$ & $2(4.3)$ \\
\hline Severe & $180(100)$ & $1(0.6)$ & $1(0.6)$ & $1(1.5)$ & $2(4.3)$ \\
\hline$P$ value* & & .069 & .065 & .67 & .72 \\
\hline
\end{tabular}

$M R$, Mitral regurgitation. *Compares first 120 cases and second 180 cases (Wilcoxon rank-sum test). 
in the first cohort with severe MR who we are following and 1 patient in the later cohort. One of these patients in the first group had a P2 triangular resection and placement of an ATS band with follow-up echocardiograms showing mild MR. He is currently asymptomatic. The other 3 patients in group 1 had annular dilatation and were treated with ATS bands. They currently have moderate MR and are asymptomatic with medical management. Our practice is to use a complete ring for these patients because a partial ring might not provide the best annular stabilization at different loading conditions. The 2 patients in the second group with severe MR remain asymptomatic. We had a total of 9 patients requiring MV replacement for failed repair at the time of surgery. We performed a sternotomy in 8 of the 9 patients and a minimally invasive mitral replacement in 1 patient. The failure rate and use of sternotomy decreased between our first 120 and second 180 cases. Our decision to use a sternotomy in these cases varied from endocarditis and poor visualization and access. We did not use the robot for the replacement because we thought we required more experience before performing robotic MV replacements. With our increased experience and the experience of other centers, we are expanding our program to include robotic MV replacement. ${ }^{15}$

\section{Learning Curve and Training}

Team learning curve also is important when developing a robotic program. When examining our results, we find that we had improved success and decreased clamp time in more complex patients in the last 180 patients compared with the first 120 patients. In addition, repair failures requiring a second operation were reduced in the second era despite the significantly increased frequency of more complex pathology and repairs. The majority of complications and reoperations occurred early in our experience, especially using the first-generation da Vinci robot. We strongly believe that team experience and center volume are crucial components to a successful program and results. For the second cohort, we began training our new mitral surgeon on the da Vinci system. This was done in a stepwise fashion until the surgeon progressed to performing the entire case. Our overall success rate was $97 \%$, which is comparable to other large series $^{7,8,10,13,16}$; however, when examining our success rate for the second cohort, it was $99 \%$, demonstrating improved experience. Furthermore, the success rate in the second cohort includes the addition of a new robotic mitral surgeon.

Intuitive Surgical, Inc has developed a pathway for training surgeons in cardiac surgery described by Ben-Or and colleagues ${ }^{17}$ and Chitwood and colleagues. ${ }^{18}$ The training starts with an introduction to the system followed by online system training. The next step is an in-depth training at one of the training centers followed by observation of a live procedure. It is then recommended to start the initial case within 60 days preferentially by 2 weeks. Chitwood and colleagues ${ }^{18}$ recommend that a surgeon should perform at least 1 to 2 robotically assisted procedures every 4 weeks to maintain proficiency.

We believe the described strategy has some limitations. First, at the end of training, the new robotic surgeon still has a significant learning curve to overcome and is vulnerable to making errors or having complications that senior operators know to avoid and prevent. Second, young staff may not have yet developed a sufficient practice to have enough cases to stay proficient and reduce operating room time. Because of those limitations, we developed a systematic approach to robotic training. To reduce the learning curve and decrease the risk of complications, the procedure was divided into 5 steps: (1) opening and setup; (2) closure of left atriotomy; (3) annular sutures (medial aspect); (4) annular suture (lateral aspect); and (5) leaflet work. Once all steps were completely mastered, the new surgeon progressed to performing the entire case. We strongly believe that this stepwise approach prevents complication and increases case efficiency. Our results demonstrate that training a new surgeon has no impact on outcomes. Our data show that training of a new surgeon had little impact on pump time and no impact on complication rate. This stepwise approach of training a new surgeon with an established robotic surgeon resulted in a shorter learning curve with the added benefit of preventing complications that are seen by novice surgeons. Our experience showed that the learning curve can be effectively reduced by using a robust training program. When comparing the first case times for each surgeon, we see a significant difference (operating room time: 5 hours 29 minutes vs 4 hours $11 \mathrm{mi}$ nutes; pump time: 213 minutes vs 130 minutes; and crossclamp: 178 vs 90 minutes).

Maintenance of proficiency is an important component to maintaining good outcomes and a viable robotic program. This can be difficult for new mitral surgeons because their practices may not be large enough to perform the 10 to 15 simple repairs at a frequency of 1 to 2 cases per month as suggested by Ben-Or and colleagues ${ }^{17}$ and Chitwood and colleagues. ${ }^{18}$ We have developed a strategy of developing a centralized mitral clinic where the patients are seen by both surgeons and the case is performed by both surgeons, allowing for maintenance of proficiency, improved experience and results, and quicker pace than would be achieved by a new mitral surgeon.

\section{Echocardiographic Results}

Post-pump echocardiograms showed no/trace MR in $86.1 \%$ of the last 180 cases and mild MR in $11.1 \%$. Follow-up echocardiography from 1 month showed no/ trace MR in $70.7 \%$ of patients and mild MR in $21.7 \%$ of the last 180 patients. Compared with results from other large centers, our results are comparable albeit at the higher 
spectrum. Suri and colleagues ${ }^{13}$ showed an $18 \%$ incidence of mild MR. We hypothesize that scarring over time after triangular resection may restrict the leaflet and result in mild MR in the early to mid-term. However, the freedom from moderate to severe MR at more than 1 year was $91.4 \%$ in the second cohort. Our results are comparable to those of similar large institutions. McClure and colleagues $^{19}$ reported an $88 \%$ freedom from moderate to severe MR. We believe that robotic mitral repair offers excellent outcomes with minimal risk and morbidity.

\section{Complications}

We observed a low incidence of major adverse cardiac events and only 1 death in the entire cohort, which was in the first 120 patients. Strokes can be devastating, and there were 6 neurologic events in the overall experience: 4 $(3.3 \%)$ in group 1 and $2(1.7 \%)$ in group 2 . Although 1 patient had persistent deficits in the first cohort, none had any residual deficit in the second cohort. There were no neurologic events in the last 120 patients after instituting our routine use of computed tomography scan to assess for aortoiliac disease.

Two occluded coronaries have occurred in this entire series, 1 in each cohort. Both patients are currently asymptomatic. Both occlusions occurred during the learning curves of each surgeon. Injury to the circumflex is a recognized complication after mitral surgery. We routinely evaluate the coronary arteries with an angiogram or a coronary angiogram looking for coronary artery disease and for right or left dominance. We are particularly careful with our stitches in left dominant coronary systems. We also examine the postoperative TEE for any wall motion abnormalities. Despite this, we had 1 patient with a nearly occluded obtuse marginal in the first group requiring intervention with a stent and 1 patient in the second cohort with a distally occluded obtuse marginal requiring no intervention. Although the number of coronary occlusions is small, they occur at a higher frequency. This incidence is a result of a loss of tactile sensation of depth with the robot. This complication is avoided by using visual clues to prevent coronary kinking or occlusion. Since the discovery of these 2 patients, we have modified our technique to minimize the risk for coronary kinking. We use visual clues to gauge depth and take particular care when approaching the annulus near the circumflex. We also take less of a bite in that location to minimize the risk of kinking.

Overall, we have demonstrated improved clinical outcomes with decreased crossclamp time in a cohort of patients with more complex mitral pathology. In addition, mitral repairs in our last 180 patients were more extensive. The newer da Vinci system together with increased experience has made robotic MV repair of all types of degenerative MV pathology reproducible and safe. The training of young surgeons in a stepwise fashion in high-volume centers will help to avoid the complications encountered during the introduction of this technology and improve overall results.

\section{Study Limitations}

This is a single-institution retrospective clinical study with only 2 surgeons represented. The lack of late followup for the entire cohort is a limitation, but $97 \%$ of patients were seen and echocardiograms were performed at least once postoperatively, which provide strong support for our data.

\section{CONCLUSIONS}

Robotic mitral surgery is safe and effective. Furthermore, training new mitral surgeons can be done safely and in a way that reduces the learning curve and eliminates novice errors.

\section{References}

1. Carpentier A. Cardiac valve surgery-the "French correction" J Thorac Cardiovasc Surg. 1983;86:323-37.

2. Lawrie GM. Mitral valve: toward complete repairability. Surg Technol Int. 2006; 15:189-97.

3. Casselman FP, Van Slycke S, Dom H, Lambrechts DL, Vermeulen Y, Vanermen H. Endoscopic mitral valve repair: feasible, reproducible, and durable. J Thorac Cardiovasc Surg. 2003;125:273-82.

4. Casselman FP, Van Slycke S, Wellens F, De Geest R, Degrieck I, Van Praet F, et al. Mitral valve surgery can now routinely be performed endoscopically. Circulation. 2003;108(Suppl 1):II48-54.

5. Falk V, Walther T, Autschbach R, Diegeler A, Battellini R, Mohr FW Robot-assisted minimally invasive solo mitral valve operation. J Thorac Cardiovasc Surg. 1998:115:470-1.

6. Grossi EA, Lapietra A, Applebaum RM, Ribakove GH, Galloway AC, Baumann FG, et al. Case report of robotic instrument-enhanced mitral valve surgery. J Thorac Cardiovasc Surg. 2000;120:1169-71.

7. Felger JE, Nifong LW, Chitwood WR Jr. The evolution and early experience with robot-assisted mitral valve surgery. Curr Surg. 2001;58:570-5.

8. Felger JE, Chitwood WR Jr, Nifong LW, Holbert D. Evolution of mitral valve surgery: toward a totally endoscopic approach. Ann Thorac Surg. 2001;72: 1203-9.

9. Cheng W, Fontana GP, De Robertis MA, Mirocha J, Czer LS, Kass RM, et al. Is robotic mitral valve repair a reproducible approach? J Thorac Cardiovasc Surg. 2010;139:628-33.

10. Nifong LW, Rodriguez E, Chitwood WR Jr. 540 consecutive robotic mitral valve repairs including concomitant atrial fibrillation cryoablation. Ann Thorac Surg. 2012;94:38-43.

11. Suri RM, Antiel RM, Burkhart HM, Huebner M, Li Z, Eton DT, et al. Quality of life after early mitral valve repair using conventional and robotic approaches. Ann Thorac Surg. 2012;93:761-9.

12. Suri RM, Burkhart HM, Daly RC, Dearani JA, Park SJ, Sundt TM 3rd, et al. Robotic mitral valve repair for all prolapse subsets using techniques identical to open valvuloplasty: establishing the benchmark against which percutaneous interventions should be judged. J Thorac Cardiovasc Surg. 2011;142:970-9.

13. Suri RM, Burkhart HM, Rehfeldt KH, Enriquez-Sarano M, Daly RC, Williamson EE, et al. Robotic mitral valve repair for all categories of leaflet prolapse: improving patient appeal and advancing standard of care. Mayo Clin Proc 2011;86:838-44.

14. Svensson LG, Atik FA, Cosgrove DM, Blackstone EH, Rajeswaran J, Krishnaswamy G, et al. Minimally invasive versus conventional mitral valve surgery: a propensity-matched comparison. J Thorac Cardiovasc Surg. 2010; 139:926-32, e921-2.

15. Gao C, Yang M, Xiao C, Wang G, Wu Y, Wang J, et al. Robotically assisted mitral valve replacement. J Thorac Cardiovasc Surg. 2012;143:S64-7. 
16. Chitwood WR Jr, Rodriguez E, Chu MW, Hassan A, Ferguson TB, Vos PW, et al. Robotic mitral valve repairs in 300 patients: a single-center experience. $J$ Thorac Cardiovasc Surg. 2008;136:436-41.

17. Ben-Or S, Nifong LW, Chitwood WR Jr. Robotic surgical training. Cancer J. 2013;19:120-3.
18. Chitwood WR Jr, Nifong LW, Chapman WH, Felger JE, Bailey BM, Ballint T, et al Robotic surgical training in an academic institution. Ann Surg. 2001;234:475-86.

19. McClure RS, Cohn LH, Wiegerinck E, Couper GS, Aranki SF, Bolman RM 3rd, et al. Early and late outcomes in minimally invasive mitral valve repair: an elevenyear experience in 707 patients. J Thorac Cardiovasc Surg. 2009;137:70-5. 